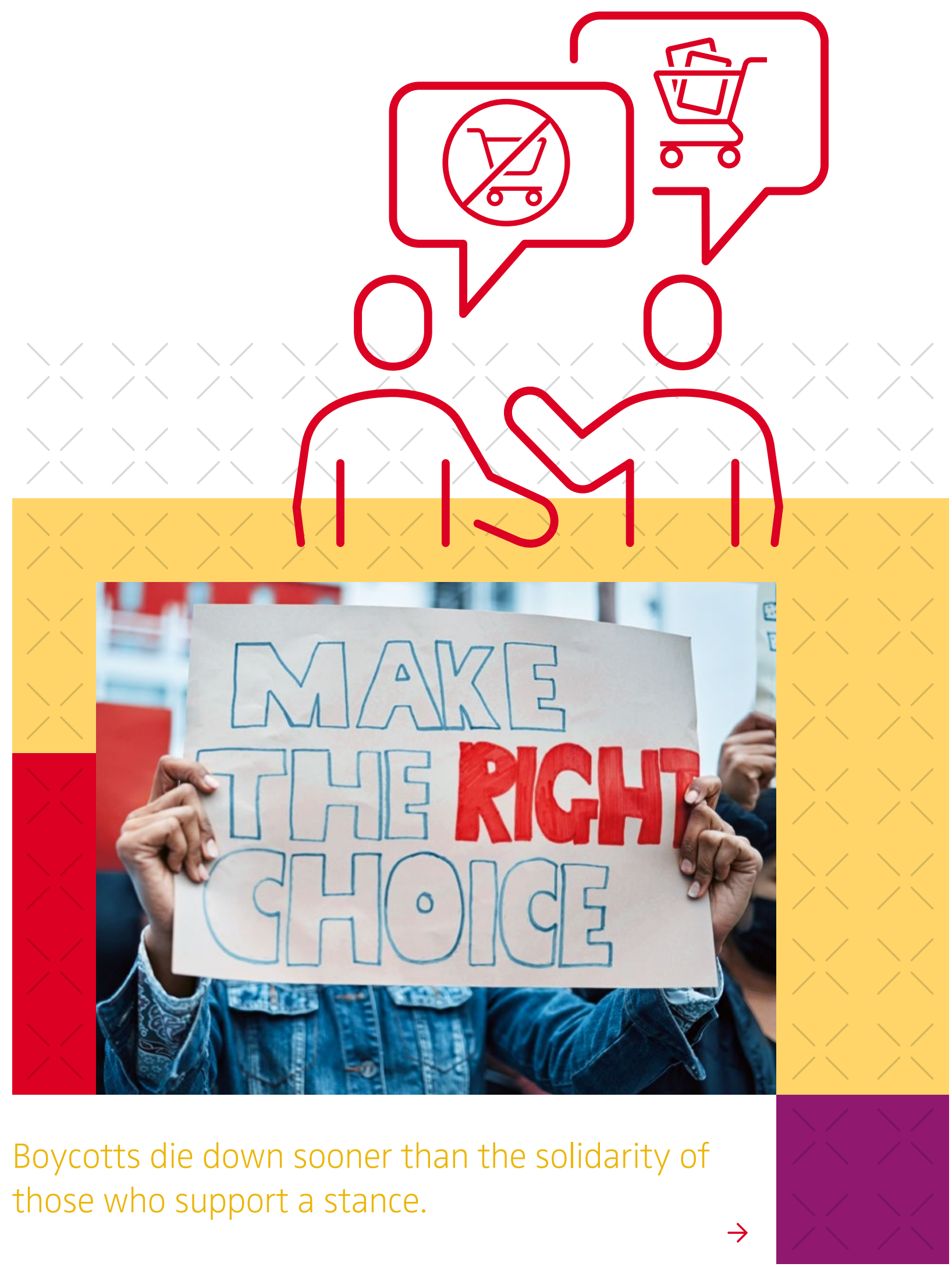




\title{
Boycott or Buycott: The Aftermath of Corporate Activism
}

\author{
Nooshin L. Warren
}

KEYWORDS

\section{Corporate Activism, Boycott, Buycott, Socio-Political Risks}

\section{THE AUTHOR}

\section{Nooshin L Warren}

Assistant Professor of Marketing, Eller College of Management, University of Arizona, USA

nwarren@arizona.edu
A new era of corporate socio-political activism $`$ Our times are characterized by many controversial socio-political issues, and social media allow all forms of crowds to join the discussion of polarizing matters such as racial justice, gender issues, immigration, and social justice. But not only do more and more consumers passionately support or oppose controversial issues, they also increasingly expect brands and companies to serve a purpose and to publicly stand up for or against these matters. And many brands actually do. For instance, Nike launched an ad, using Colin Kaepernick as their spokesperson, supporting his protest against police brutality and racial discrimination. Other brands rainbow-color their logos to support pride month and the LGBT community. Some companies take more conservative positions, like Chick-fil-A, who posted messages condemning marriage equality ruling. But no matter what message or stance, there will always be supportive as well as opposing and angry customers. While the first group will take their support and solidarity to social media, opponents often join forces and stir \#boycott or post videos destroying products. The decision to participate in activism is therefore critical to managers.

Boycott vs. Buycott: What will prevail? $\times$ Whether and how critical stakeholder groups will react to activism is often difficult to predict. Happy customers will try to reward the company, while angry customers might take action to punish it. Will polarizing stances and hence willingly upsetting some customers ultimately pay off? Some stakeholders, notably investors, might be worried that debatable activism interferes with the goal of making profits and might therefore 
BOX 1

\section{Investigating effects of brand activism on stock prices and sales}

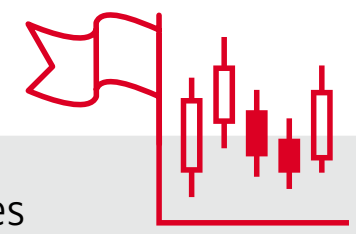

In our study, my colleagues and I collected data on close to 300 brand activism events from 142 publicly held U.S. companies in 39 industries between 2011 and 2016. Figure 1 shows examples of the events we investigated. We concentrated our analysis on two key factors, namely stock prices and sales, and analyzed how investors and customers reacted to brand activism events. We further analyzed the impact of alignment between the stance of a company's activism and the value system of employees and customers, as well as the political orientation of state governments. We show that the misalignment of activism with each of their stakeholders can affect company value. Such stakeholder value-driven performance can make activism even more complex, as not all companies enjoy stakeholders who all hold similar political ideologies.

Among the examples in Figure 1, Lowe's enjoyed support from all their conservative consumers, employees, and legislatures in North Carolina, and JC Penny's liberal support of the LGBTQ community was condemned by their conservative consumers and employees and by their Texan legislatures. However, other companies face differential reactions among their stakeholders. For instance, Target's liberal support of the LGBTQ community is aligned with the value system of their consumers and the government legislature in Minnesota, but it does not reflect the conservative leaning value system of the majority of its employees' value system.

Brand activism affects stock prices $\rtimes$ On average, there was a half percent dip in stock prices as companies engaged in activism. While this figure seems small, it can still mean millions for giant companies. For Nike, for instance, a half percent less per share means a drop of its company value by almost 500 million US\$ within a week. Looking more closely at the effects, activism can cause positive investor reactions as well. If the activism was aligned with a company's stakeholders' values, stock prices increased. The effect for customer and legislators was stronger than for employees in a comparison of groups with a high and low alignment of values, as Figure 2 shows. Misalignment with all three groups accounts for a loss of about $3 \%$ in share price.

Brand activism tends to increase sales $\times$ On average, brand activism aligned with consumers political ideologies increased sales, and the positive effects were persistent over time. While companies experienced some sales losses, when the activism did not align with the values of their customers, the sales gains in case of high alignment were substantial and affected not only quarterly, but also annual sales significantly (see Figure 3). When not only customer values aligned, but also those of legislators and employees, sales effect was strongest with an increase by $12 \%$ annually.

react negatively. There is indeed reason to be cautious: Studies in psychology and journalism tell us that angry tweets and videos attract more attention and grab more time and volume on social media than positive emotions, an effect called negativity bias. In a research project, we investigated whether and under which conditions social activism of brands can still be a worthwhile strategy.

Boycotts die down soon $\times$ In the context of activism, harmful counteractions of consumers seem less consequential than in other contexts: According to our findings, boycotts die down sooner than the solidarity of those who support a stance. Nike, for instance, observed sales growth of over $30 \%$, despite the outrage over their Kaepernick ad. Brand activism has the power to shape brand identity and to make customer connections stronger. Customers prefer relationships with brands that have a purpose similar to their own value system and identify with the demonstrated beliefs. These relationships are longer-lasting than reactions based on anger. Therefore, brand activism can serve as a strategic option for growing a company's business rather than being a costly sideshow that investors need to get nervous about. However, controversial stances are slippery ground and activism needs to be planned and executed cautiously.

A roadmap for successful socio-political activism $\times$ The following recommendations will help companies to navigate on the slippery grounds of corporate activism more successfully. 
FIGURE 1 > Examples of corporate socio-political activism (CSA) included in the sample of the study

Amazon removes Confederate flag merchandise from its website.

Target supports national LGBTQ pride month \#takepride.

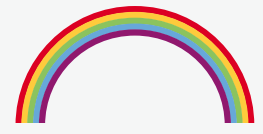

Chipotle prohibits guns in stores.

Lowe's pulls its advertising during the TLC network's All-American Muslim reality TV show.

Twitter marks Black Lives Matter movement with special emoji.

JC Penney's features two lesbian mothers in 2012 Mother's Day advertisement.

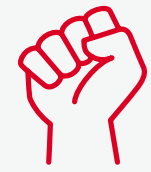

Kroger issues a statement in support of its policy for carrying firearm in the store.

The Dorito brand (PepsiCo) introduces Doritos Rainbows chips, the first Doritos product

in history made up of multiple, rainbow-colored Doritos chips inspired by the Pride flag.

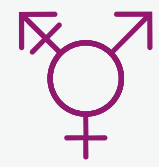

\section{$\gg$ \\ If the activism was aligned with a company's stakeholders' values, stock prices increased.}

$\ll$

FIGURE 2 > Investor reactions to socio-political activism (CSA) based on its alignment with stakeholders' values

Level of CSA Alignment

With Customers

Cumulative Abnormal Returns

With Employees

Cumulative Abnormal Returns

With Legislators

Cumulative Abnormal Returns

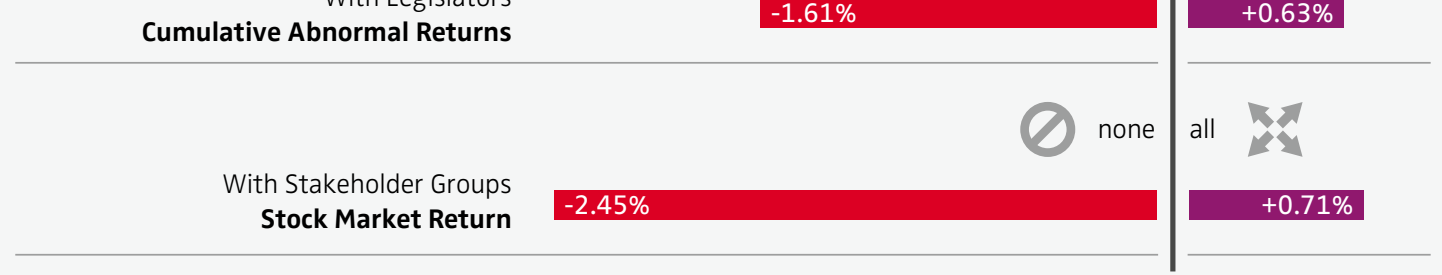




\title{
$\gg$ On average, brand activism aligned with consumers political ideologies increased sales, and the positive effects were persistent over time.
}

\author{
$\ll$
}

FIGURE $3>$ How customers react to corporate socio-political activism (CSA)

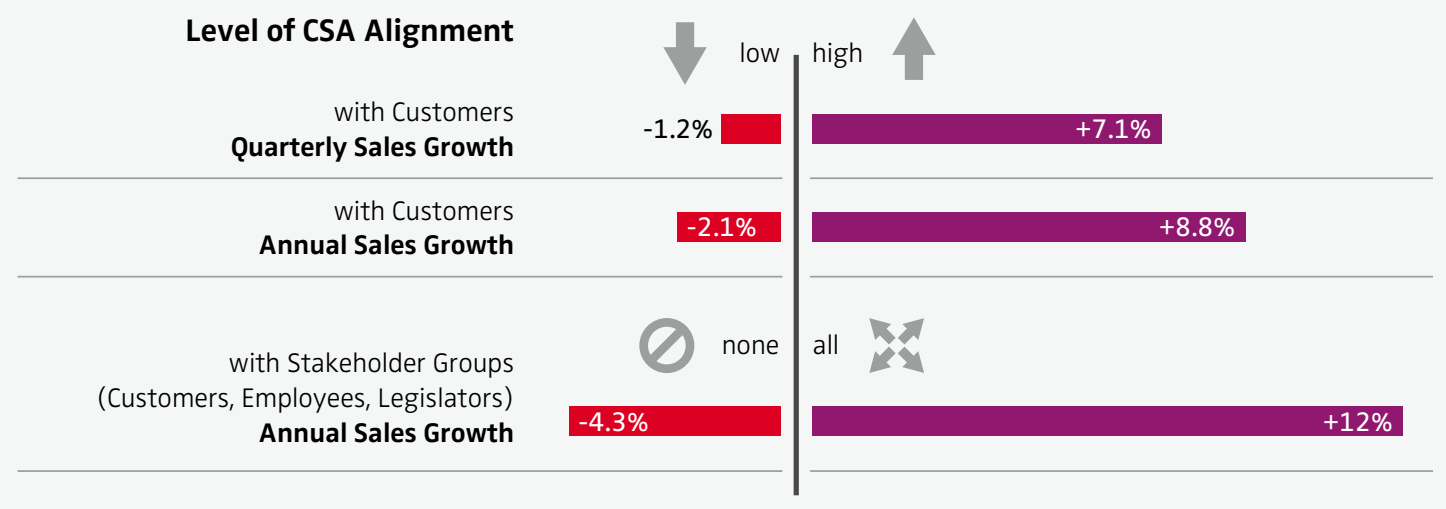

$>$ Pick your issues carefully $\ltimes$ To be successful, companies should carefully select their engagements to avoid being punished. When deciding whether to engage in controversial activism, they should have a closer look at key stakeholders, such as customers, regulators, and employees. Our study has shown that alignment with customer values is particularly relevant, not only for sales, but also for investor reactions.

$>$ Communicate your commitments strategically $\times$ As investors often seem to be skeptical about the strategic value of activism, it is important to explain the motives for engagement as well as its scope and the expected returns. Investors tended to punish actions more than mere statements and reacted more negatively when an initiative was announced by a company's CEO, compared to any other representative. In these cases, investors seemed to fear that investments into a debatable societal cause might be at the cost of company profits. In contrast, companies that explained that their stances also supported their business interests experienced positive, rather than negative, reactions from investors. The financial consequences of corporate activism, therefore, depend on who announces it and how well it convinces key stakeholders of the strategic worth of taking sides in a controversial debate.

$>$ Join forces with other brands $\ltimes$ When you expect no clear position among your customers and stakeholders, teaming up with other companies can be an option. The Tech Giants and other Silicon Valley companies, as an example, joined forces to support the call for marriage equality and urged the supreme court to declare right to same-sex marriage. Their leaders backed their moral appeal with financial arguments. When companies collec- 


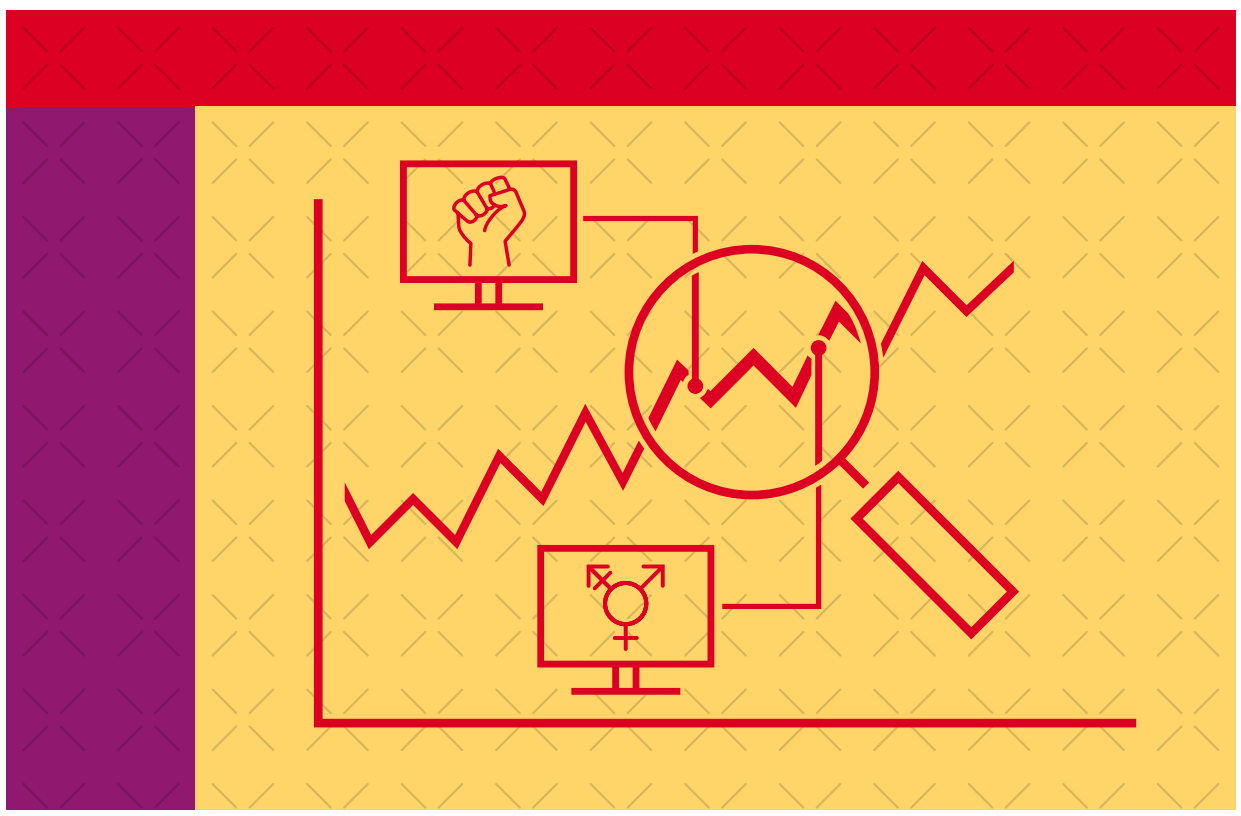

tively conduct activism, the issue seems more normal and more widely supported. The blame gets divided between the participant companies, and the negative effect gets smaller.

$>$ Walk the talk in your entire organization ׳ Even if the financial consequences can be positive, companies should not engage in activism as a mere profit-seeking strategy. They need to convince society of their authenticity. Consumers who care for an issue will hold companies accountable for all corporate actions and have an eye on whether companies' internal and external behavior reflect the issue a company publicly supports. If you stand up for diversity and racial justices and do not sufficiently implement equal rights in your own workforce or board, you will likely experience backlash. In the U.S., Adidas' chief of human resources had to resign for not handling racial issues in the workplace adequately. Cheap talk is likely to be punished, even if the called-out values are shared with customers or employees.
In polarized societies, taking sides is risky, but not taking sides has its risks, as well as many customers prefer doing business with brands and companies that have a purpose beyond mere business objectives. A prior analysis of potential risks and a sound implementation of corporate activism can help move society into the desired direction and support financial goals as well.

$\downarrow$

KEY REFERENCE AND FURTHER READING

Bhagwat, Y.; Warren, N. L.; Beck, J. T.; \& Watson, G. F. (2020): "Corporate Sociopolitical Activism and Firm Value", Journal of Marketing, Vol. 84(5), 1-21. https://doi.org/10.1177/0022242920937000 